\title{
Modelling glaciers bed overdeepenings and possible future lakes in deglaciating landscapes of the French Alps
}

\author{
Maeva Cathala ${ }^{1}$, Florence Magnin ${ }^{1}$, Andreas Linsbauer ${ }^{2,3}$, Wilfried Haeberli ${ }^{2}$, Ludovic Ravanel ${ }^{1}$, \\ and Philip Deline ${ }^{1}$ \\ ${ }^{1}$ EDYTEM Lab, University Savoie Mont Blanc, CNRS, 73376 Le Bourget du Lac, France \\ ${ }^{2}$ Geography Department, University of Zurich, 8057 Zurich, Switzerland \\ ${ }^{3}$ Department of Geosciences, University of Fribourg, Switzerland
}

Alpine glacier retreat due to global warming generates major landscape changes in high mountain environments. New lakes can potentially form in Glaciers Bed Overdeepenings (GBOs). Those new water bodies, sometimes located near potentially instable slopes or behind unstable moraine dams, can increase outburst flood hazards, generating risks for valley floors. Such GLOF events (Glacial Lake Outbrust Floods) can result from displacement waves triggered by rock fall into lakes and/or sudden dam breaching. Those events can travel far down to low altitude areas and turning into high magnitude debris flows. Beyond the threats, those lakes can also represent opportunities for tourism, hydropower production or fresh water supply.

Anticipating location and formation of potential future lakes is thus essential for risk mitigation and seizing the opportunities. In the French Alps so far, potential future lakes have only been investigated in the Mont Blanc massif, while several other glaciated high mountain ranges may also yield water bodies in the near future. This study aims to identify and characterize the location of potential future lakes for each mountain massif of the French Alps (mainly the Mont Blanc, Grandes Rousses, Vanoise and Écrins massifs).

To do so, we first ran GlabTop model, a GIS scheme calculating ice thickness from surface slope via basal shear stress, to map potential GBOs. We also ran GlabTOP 2, which is based on the same concept but is fully automated. In this study, we compared the results between GlabTop and GlabTop 2. We then estimated the level of confidence of the predicted GBOs using morphometric analysis (slope angle at GBOs and downstream, presence/absence of crevasse fields, presence/absence of bedrock threshold) and classification of lakes according to their susceptibility of formation.

GlabTOP output thus revealed 89 GBOs (>1ha) which can potentially be sites for future lakes. 20 
lakes are predicted in Écrins, 2 in Grandes Rousses, 39 in Vanoise and 30 on the French side of the Mont Blanc massif. The lakes with the highest surfaces/thicknesses are situated in the latter. Among the 89 predicted water bodies, 41 are highly susceptible to be formed. Some can already be observed in GBOs in recently deglaciated areas like at the Bionnassay and Tré la Tête glaciers (Mont Blanc massif).

This communication will present the approach, the detailed results and possible implications for landscape management at the French Alps scale. 